\title{
DIFERENÇAS APARENTES, ANALOGIAS PROFUNDAS E O ANJO ESCARLATE DA MANHÃ - Aprendizado e leitura em la Prisonnière de Marcel Proust.
}

\author{
por Samira Murad ${ }^{1}$
}

\begin{abstract}
RESUMO: O objetivo deste artigo é discutir como o movimento de analogia profunda observado na Recherche du Temps Perdu supõe a produção complementar da diferença. Essa "prática" deve ser aprendida e executada pelo herói em seu caminho para tornar-se narrador e é, portanto, o elemento que o distingue da grande massa de personagens do romance. $\mathrm{O}$ aprendizado é visto pela crítica proustiana como a unidade da Recherche e o volume La Prisonnière é etapa fundamental nesse processo. A função narrativa do aprendizado parece ser, entretanto, outra e passa pelo que Proust chama de "longa demonstração" de uma "obra dogmática", ligada ao papel que o leitor deve assumir durante a leitura do romance.
\end{abstract}

PALAVRAS-CHAVE: analogia, diferença, aprendizado, La Recherche du temps perdu, leitor.

RÉSUMÉ: Le but de cet article est de discuter comment le mouvement de l'analogie profonde qu'on observe dans La Recherche du temps perdu est liée au mouvement complementaire de la différence. La pratique de la différence doit être appris par le héros de la Recherche et elle est l'élément qui peu distingue ce héros du reste des personnages. L'apprentissage est vue par la critique proustienne comme l'unité de la Recherche et le volume La Prisonnière est une de ces etapes fondamentales. Pourtant, la fonction narrative de l'apprentissage semble être liée à ce que Proust appelle sa "longue démonstration" et donc, elle détermine le rôle du lecteur dans la Recherche du temps perdu.

MOTS CLÉS: analogie, différence, apprentissage, La Recherche du temps perdu,lecteur.

Em um dos mais estimulantes textos já escritos sobre a Recherche du Temps Perdu, o filósofo Gilles Deleuze (1987, p. 88) mostra como a "explicação" é um dos grandes movimentos do romance. Ela consiste no desenrolar de um fio de sentido que liga, transversalmente, dois objetos diferentes num processo de analogia profunda. A fim de que esse movimento funcione em toda sua força, o narrador deve aprender a exercitar sua capacidade de precisão, numa prática da diferença.

O aprendizado que se dá, entre outras coisas, na oscilação entre a analogia e a diferença é visto pela crítica como a essência do texto proustiano e sua possível unidade, uma vez que o romance parece funcionar como o relato, não de uma vida, mas de um "desejo de escrever".(BARTHES, 2002, p.459). Esse desejo, incipiente e hesitante no início,vai se modificando no decorrer da história até o episódio na casa da Princesa de Guermantes. Nele, o narrador descobre a natureza de seu projeto e decide iniciar o trabalho que, na verdade, acabamos de ler. A Recherche du Temps Perdu fecha-se, assim, sobre si mesma, numa perfeita circularidade. Entretanto, se o processo de aprendizagem do narrador não coincide com a do autor (ou permite supor, ao menos, um novo salto no tempo) por que utilizar tal percurso como a unidade do romance? Dito de outro modo, qual é a natureza e função narrativa do chamado "aprendizado"?

\footnotetext{
${ }^{1}$ Samira Murad possui mestrado em Língua e Literatura Francesa pela Faculdade de Filosofia, Letras e Ciências Humanas da Universidade de São Paulo. Atualmente, é doutoranda nesta universidade, desenvolvendo pesquisa sobre os manuscritos de Georges Perec e Marcel Proust. Faz parte do Projeto Brépols brasileiro e do Grupo Criação e Crítica. Publicou os ensaios "Irmãos Inimigos? Crítica Genética e Teoria do Efeito Estético em Le Voyage d'hiver de Georges Perec." (Criação em debate, Humanitas, 2007) e "Georges Perec:o anti-Proust?" (Revista de Letras da Unesp,São Paulo, v.48, n.1, jan./jun.2008.)
} 
Essas são algumas das questões que tento desenvolver neste artigo.Começarei, portanto, tentando mostrar como, no próprio nível lexical do texto, apresenta-se a questão da analogia e da diferença. A seguir, mostro como essa última desenvolve-se de maneira exclusiva na esfera do narrador e, conseqüentemente, está ausente da caracterização de personagens como Swann, Charlus e Albertine (daí a importância de La Prisonnière no desenvolvimento do romance como um todo). A prática da diferença parece ser, então, um dos elementos essenciais do aprendizado, o qual se desenvolve também por uma série de avanços e retrocessos na visão de arte do narrador. Finalmente, tento mostrar como o aprendizado relaciona-se com o papel do leitor no romance.

\section{O MOVIMENTO DA ANALOGIA PROFUNDA:}

Num trecho que trata do septeto de Vinteuil, o narrador proustiano diz:

...et pourtant, ces phrases si différents étaient faites des mêmes éléments (...), ces deux interrogations si dissemblables qui commandaient le mouvement si différent de la sonate et du septuor, l'une brisant en courts appels une ligne continue et pure, l'autre ressoudant en une armature indivisible des fragments épars, l'une si calme et timide, presque détachée et comme philosophique, l'autre si pressante, anxieuse, implorante, c'était portant une même prière, jaillie devant différents levers de soleil intérieurs, et seulement réfractée à travers les milieux différents de pensées autres (...) et c'était justement quand il cherchait puissamment à être nouveau, qu'on reconnaissait, sous les différences apparentes, les similitudes profondes et les ressemblances voulues qu'il y avait au sein d'une œuvre, quand Vinteuil reprenait à diverses reprises une même phrase, la diversifiait, s'amusait à changer son rythme à la faire reparaître sous la forme première, ces ressemblances-là voulues, œuvre d'intelligence, forcement superficielles, n'arrivaient jamais à être aussi frappantes que ces ressemblances dissimulés, involontaires, qui éclataient sous des couleurs différents, entre les deux chefs-d'œuvre distincts... (PROUST, 1988a, pp. 759-760).

Ao atualizar esse fragmento, o leitor não pode deixar de perceber a força da oscilação entre a série que denota a idéia de "diferença" e a que denota "analogia". Adjetivos como "différent", "dissemblables", "nouveau", "différences" chocam-se continuamente com um léxico que aponta para a produção de semelhança. Ficamos sabendo que o septeto e a sonata são "une même prière" e apresentam "des similitudes profondes" e "ressemblances involontaires".

Gilles Deleuze (1987) quer dar conta dessa força quando propõe as noções de "implicação" e "explicação", vistas como as duas grandes categorias da Recherche du Temps Perdu. A "implicação" ou "envolvimento" está ligada ao sentido que, implicado no signo, "é como que uma coisa enrolada em outra"(DELEUZE , 1987, p. 89). Já a categoria de "explicação" está na capacidade de desenrolar esse fio de sentido que ocorre, por exemplo, quando:

[...]O amante ciumento desenvolve os mundos possíveis encerrados na criatura amada (e) o homem sensível libera as almas implicadas nas coisas, mais ou menos como quem vê os pedaços de papel do jogo japonês desdobrando-se na água, estirando-se ou explicando-se, ao formar flores, casas e personagens...(DELEUZE, 1987, p. 89) 
Em La Prisonnière essa "explicação" da "alma implicada" nas coisas manifesta-se, por exemplo, no episódio em que o narrador, em conversa com Albertine, ouve sua própria voz e pensa “ ... entendre(sa) grand-mère. Du reste, n'était-il pas arrivé à ma mère (...) de croire que c'était mon père qui entrait, tant j'avais ça même manière de frapper que lui ...» (PROUST, 1988a, p. 615).

\section{A PERCEPÇÃO AGUDA - ÍNDICE DO MOVIMENTO COMPLEMENTAR DA DIFERENÇA:}

O fenômeno apresentado acima é descrito pelo narrador como a "lei da vida" ou a "reunião de elementos contrários" (PROUST, 1988, p. 615). De fato, é a "alma" ou a "essência" da família que se apresenta em seus diferentes membros que parecem confundir-se, numa analogia profunda que supera a aparência individual e que já se encontrava prefigurado no episódio da madalena, quando a "alma" de Combray desdobra-se a partir da xícara de chá do herói.

Para que essa busca da analogia funcione, o narrador deve aprender a exercitar sua "percepção aguda", definida por Philippe Willemart (2002, p.163) como a "capacidade (...) de entender uma mensagem lançada ao ar" e ultrapassar "a primeira percepção muitas vezes falsa ou mal focalizada". Essa busca lembra o que Calvino chama de "precisão", um dos valores, que defende ser retido para a literatura do século XXI.

Na conferência chamada de "Exatidão", Calvino (1990, p. 75) faz um elogio desse valor a partir de seu oposto e descobre que:

[...]para se alcançar a imprecisão desejada, é necessário a atenção extremamente precisa e meticulosa que ele (Leopardi) aplica na composição de cada imagem, na definição minuciosa dos detalhes, na escolha dos objetos, da iluminação, da atmosfera (...) a procura do indeterminado se transforma em observação da multiplicidade, do fervilhar, da pulverulência...

Essa busca do indeterminado, que em Proust parece traduzir-se na busca na reunião de elementos contrários, acaba por produzir a necessidade complementar de precisão, a "definição minuciosa dos detalhes", pois não haveria mérito algum na analogia se os elementos não fossem diferenciados anteriormente.

Logo na abertura de La Prisonnière, podemos ver esse extraordinário movimento perceptivo de exatidão em ação:

[...] Dès le matin, la tête encore tournée contre le mur et avant d'avoir vu, au-dessus des grands rideaux de la fenêtre, de quelle nuance était la raie du jour, je savais déjà le temps qu'il faisait. Les premiers bruit de la rue me l'avaient appris, selon qu'ils me parvenaient amortis et déviés par l'humidité ou vibrants comme des flèches dans l'aire résonnante et vide d'un matin spacieux, glacial et pur ; dès le roulement du premier tramway, j'avais entendu s'il était morfondu dans la pluie ou en partance pour l'azur. Et peutêtre ces bruits avaient-ils été devancés eux-mêmes par quelque émanation plus rapide et plus pénétrante qui, glissée au travers de mon sommeil, y répandait une tristesse annonciatrice de la neige, ou y faisait entonner, à certain petit personnage intermittent, de si nombreux cantique à la gloire du soleil que ceux-ci finissaient par amener pour moi, qui encore endormi commençais a sourire et dont les paupières closes se préparaient à être 
éblouies, un étourdissant réveil en musique. (PROUST,

1988a,

P. 519)

PROBLEMAS DE PERCEPÇÃO - OS “RASCUNHOS” DE ARTISTA:

Para que a "percepção aguda" seja uma característica exclusiva do Protagonista, outros personagens do romance não podem demonstrar a mesma capacidade. Swann, por exemplo, não é capaz de ser preciso e diferenciar a beleza da arte e o prazer que sente com ela do prazer que sente com Odette. De fato, apaixona-se pela "coquette" porque ela faz com que pense em uma virgem de Botticelli. Isso ocorre também quando Swann sente um misto de tristeza e prazer quando ouve a pequena frase da sonata de Vinteuil mas não é capaz de ir além da sensação. É Willemart (2000, p. 160) quem comenta tal fracasso de exatidão, dizendo que é “... o amor do objeto "música" (que) impede Swann de prosseguir sua busca. Ignorando a tristeza que a sonata faz lembrar, não a utilizando para detectar o que nela se esconde, Swann será o eterno celibatário da arte".

Charlus é um outro personagem que funciona nessa chave. Em La Prisonnière, o barão, organizando uma reunião em casa de Mme. de Verdurin para ouvirem Morel, explica a Mme. Verdurin, porque não convidou Mme Molé para o evento:

[...]il faut éviter les gaffes quand nous donnons une fête qui doit être digne de Vinteuil (..) Vous auriez invité la Molé que tout était raté. C'était la petite goutte contraire, neutralisante, qui rend une potion sans vertu. L'électricité se serait éteint. Les petits fours ne seraient pas arriver à temps, l'orangeade aurait donné la colique à tout le monde. C'était la personne à ne pas avoir. A son nom seul, comme dans une féerie, aucun son ne serait sorti de cuivres ; la flûte et les hautbois auraient été pris d'une extinction de voix subite (...) j'ai très bien senti dans l'épanouissement de certain largo qui s'ouvrait jusqu' au fond comme une fleur, dans le surcroît de satisfaction du finale, qui n'était pas seulement allegro mais incomparablement allègre, que l'absence de la Molé inspirait les musiciens et dilatait de joie jusqu'aux instruments de musique eux-mêmes... (PROUST, 1988a, P. 780)

O erro de Charlus está justamente em sua pouca precisão. Incapaz de separar a esfera da arte da esfera da vida mundana, seu discurso coloca no mesmo nível os "petits fours", a "laranjada" e a música. Também sua observação final mostra que ele acredita que o andamento da música e até a performance dos instrumentos são diretamente decorrentes da ausência de Mme. Molé. Como Swann, o barão nunca foi capaz de aprofundar suas percepções e criar algo artisticamente interessante e é isso que nos mostra o comentário do narrador imediatamente posterior à fala da personagem:

[...]le monde étant le royaume du néant, il n’y a entre les mérites des différentes femmes du monde que des degrés insignifiants, que peuvent seulement follement majorer les rancunes ou l'imagination de $\mathrm{M}$. de Charlus. Et certes, s'il parlait comme le venait de faire, dans ce langage qui était un ambigu précieux de choses de l'art et du monde, c'est parce que ses colères de vielle femme et sa culture de mondain ne fournissaient à l'éloquence véritable qui était la sienne que des thèmes insignifiants. (PROUST, 1988a, p. 780-781) 
A linguagem de Charlus, esse "ambíguo precioso das coisas da arte e do mundo" é justamente o que o faz ser um modelo não aceitável na visão de arte apresenta no Le Temps Retrouvé, ainda que o narrador conceda ao barão "uma eloqüência verdadeira".

Uma terceira personagem que sofre da falta de precisão é Albertine. Nas páginas iniciais de La Prisonnière em que narrador descreve sua vida em comum com a moça, a narrativa, num certo momento, trata de elogiar o "progresso" intelectual de Albertine e as mudanças físicas que nela se processam. Porém, após o elogio, o seguinte parágrafo se apresenta:

[...]A peine entrée dans ma chambre, elle sautait sur le lit et quelquefois définissait mon genre d'intelligence, jurait dans un transport sincère qu'elle aimerait mieux mourir que me quitter: c'était les jours où je m'étais rasé avant de la faire venir. Elle était de ces femmes qui ne savent pas démêler la raison de ce qu'elles ressentent. Le plaisir que leur cause un teint frais, elles l'expliquent par les qualités morales de celui qui leur semble pour leur avenir présenter un bonheur, capable du reste de décroître et de devenir moins nécessaire au fur et à mesure qu'on laisse pousser sa barbe. (PROUST, 1988a, p. 529)

Por que, depois de discutir o 'progresso' intelectual de Albertine e elogiar sua beleza, o narrador faz um comentário ácido desses? Estaria o narrador ventilando uma raiva mal contida em relação a Albertine? Uma possível explicação residiria na necessidade de caracterizar Albertine de forma diferente do Protagonista. Apesar do seu "progresso", Albertine ainda não seria capaz de precisar as origens de suas emoções, contrariamente ao que faz, muitas vezes, o Protagonista.

\section{O APRENDIZADO COMO UNIDADE:}

Estabelecidas as diferenças entre as personagens, uma pergunta se coloca ao leitor. Por que essa força de precisão na Recherche? Qual seria sua função narrativa?

Luc Fraisse (1995, p.98) fornece algumas pistas nessa direção em L'esthétique de Marcel Proust quando explica que para Proust:

[...] le roman idéal permet d'incarner l'abstrait dans le concret (...) C'est ce que Proust appelle un roman dogmatique, et c'est ainsi qu'il définit la Recherche. Le dogmatisme est une croyance en la possibilité pour l'esprit d'accéder à une vérité. L'art consistant, selon Proust à dégager les lois de la vie, tout roman doit conduire à l'acquisition d'une vérité...

Se o romance dogmático é aquele no qual todas as partes conduzem à "verdade", os diferentes componentes do romance têm de estar articulados de modo que essa "verdade" seja atingida. Essa idéia de articulação é apresentada pelo próprio Proust na imagem da catedral ${ }^{2}$

\footnotetext{
2 “...Un roman dogmatique ne reçoit son sens que s'il s'offre comme le 'livre le plus composé, le plus concerté qu'il soit' (...) Proust compare volontiers son cycle romanesque à une cathédrale. Il écrit à un autre lecteur perspicace: 'Et quand vous me parlez de cathédrale, je ne peux pas ne pas être ému d'une intuition qui vous permet de deviner ce que je n'ai jamais dit à personne et que j'écris ici pour la première fois: c'est que j'aurais voulu donner à chaque partie de mon livre le titre: Porche I Vitraux de l'abside etc. pour répondre d'avance à la critique stupide qu'on me fait $\mathrm{d}$ manqué de construction dans des livres où je vous montrerai que le seul mérite est dans la solidité des moindres parties' (FRAISSE, 1995, p.99).
} 
na qual os diferentes fragmentos, uma vez vistos de longe, parecem fazer parte de uma mesma construção. Mas qual seria essa grande articulação?

Diferentes críticos apontaram para o fato das diversas partes da Recherche estarem articuladas em torno da descoberta da vocação artística pelo Protagonista e do aprendizado do herói para tornar-se narrador. Gérard Genette (1972, p. 75) diz que a Recherche é o desenvolvimento monstruoso da forma verbal “... Marcel devient écrivain”. Deleuze (1987, pp. 3-4) afirma que a unidade da Recherche "não consiste na memória, nem tampouco na lembrança, ainda que involuntária (...) mas no aprendizado dos signos". Jean-Yves Tadié (1971, p. 246) afirma que “... le principe unificateur de l'œuvre(...)ne peut être que la vocation artistique, telle qu'elle se manifeste dans la vie du narrateur...”. O desenvolvimento da "percepção aguda" por parte do herói estaria ligado ao desabrochar da vocação e ao aprendizado. Resta saber em que consiste tal aprendizado.

\section{O APRENDIZADO E A GRANDE FRASE HERMENÊUTICA:}

Fraisse (1995) afirma que, para o escritor, o romance dogmático deveria ter uma extensão tal que comportasse uma longa demonstração ${ }^{3}$. A maior conquista para o escritor de uma obra dogmática é a construção complexa « donc voilée » :

[...] une grande œuvre, aux yeux de Proust, doit être baignée de mystère (...) Ce livre, d'une 'composition voilée mais rigoureuse', 'd'une composition si préméditée et complexe' oblige le lecteur à suivre une sorte de stage, sous l'autorité du romancier. S'engageant dans un itinéraire minutieusement préparé pour lui, le lecteur doit traverser de nombreux moments d'incertitude et même d'erreur, pour qu'à la fin la vérité, la certitude, la compréhension se fassent jour dans tout leur éclat... (FRAISSE, 1995, p. 102)

O léxico ${ }^{4}$ utilizado por Fraisse permite aproximar essa discussão da "obra banhada de mistério" do conceito de código hermenêutico proposto por Roland Barthes. Em $S / Z$ o crítico define tal código como:

[...]l'ensemble des unités qui ont pour fonction d'articuler, des diverses manières, une question, sa réponse et les accidents variés qui peuvent ou préparer la question ou retarder la réponse ou encore; de formuler une énigme et d'amener son déchiffrement ... (BARTHES, 1970, p. 23)

A pergunta a ser respondida ao longo da Recherche - de que maneira o herói tornou-se escritor? - tem como resposta o caminho percorrido no aperfeiçoamento de sua percepção e cujos obstáculos são "erros" e "incertezas". Ora, Barthes diz que uma parte fundamental do

\footnotetext{
3 «Un roman dogmatique doit couvrir l'étendue nécessaire à une ample démonstration. Sa composition de développe donc à vaste échelle. En 1912, Proust décrit ainsi celle de la Recherche : 'L' ouvrage est un roman ; si la liberté du ton l'apparente semble-t-il à des Mémoires, en réalité une composition très stricte (mais à ordre trop complexe pour être d'abord perceptible) le différencie au contraire extrêmement des mémoires'.... » (FRAISSE, 1995, p.101)

${ }^{4}$ Refiro-me aqui as palavras “incertitude”, “erreur” e vérité” utilizadas na citação anterior.
} 
código hermenêutico está justamente no "atraso da resposta". Entre o elemento inicial e o elemento final da frase hermenêutica temos o que ele chama de "morfemas dilatadores", definidos como:

[...] le leurre (dévoiement délibère de la vérité), ... l'équivoque (mélange de vérité et de leurre), ... la réponse partielle (fonction d'irriter l'attente de dévoilement)... la réponse suspendue (arrêt aphasique du dévoilement) ... et le blocage (constat de insolubilité).. (BARTHES, 1970, p. 81)

La Prisonnière é etapa fundamental no desenvolvimento dessa "longa demonstração" porque traz episódios em que o Protagonista pensa sobre sua vocação e aprende sobre ela. Um exemplo disso ocorre no episódio do Trocadero em que o herói, à espera de Albertine, sentase ao piano e resolve tocar a sonata de Vinteuil. Dessa ação, surgem dúvidas sobre sua vocação e reflexões sobre a arte. O herói se pergunta se:

[...]En abandonnant en fait cette ambition, avais-je renoncé à quelque chose de réel ? La vie pouvait-elle me consoler dans l'art, y avait-il dans l'art une réalité plus profonde où notre personnalité véritable trouve une expression que ne lui donnent pas les actions de la vie ?... (PROUST, 1988a, p. 664)

E alguns parágrafos adiante, ele diz que :

[...] mais alors, autant que par l'identité que j'avais remarque tout a l'heure entre la phrase de Vinteuil et celle de Wagner, j'étais troublé par cette habilité vulcanienne. Serait-ce elle qui donnerait chez les grands artistes l'illusion d'une originalité foncière, irréductible, en apparence reflet d'une réalité plus qu'humaine, en fait produit d'un labeur industrieux ?Si l'art n'est que cela, il n'est pas plus réel que la vie, et je n'avais pas tant de regrets à avoir... (PROUST, 1988a, p. 667)

Se a arte e a vida não são muito diferentes, o herói, portanto, não perde nada abandonando sua vocação. Sabemos, porém, que para o narrador a arte é realmente a "verdadeira vida". Logo, o que se apresenta em La Prisonnière é um desvio deliberado do curso da verdade, da resposta à pergunta de como o herói tornou-se escritor. Sabemos também que esse desvio é momentâneo, pois após outras tantas etapas o herói encontra seu caminho e torna-se um escritor. Essas dúvidas em relação à arte são o que podemos chamar de desvio no caminho da resposta, um atraso, como diz Barthes, pois esse não é ainda o momento da revelação final.

Outro "atraso na resposta" observado em La Prisonnière traduz-se no "equívoco" que, segundo Barthes, é uma mistura de "engano e verdade". No episódio do septeto, o herói se encontra na casa dos Verdurin para uma apresentação de Morel. A música que tocam é de Vinteuil, uma obra inédita. O herói, ouvindo a composição, inicia outra reflexão sobre a arte:

[...]au sein de ce septuor, des éléments différents s'exposaient tour a tour pour se combiner a la fin, de même, sa sonate, et comme je le sus plus tard, ses autres œuvres, n'avaient toutes été par rapport à ce septuor que de timides essais (...) et je ne pouvais m'empêcher, par comparaison, de me rappeler que, de même encore, j'avis pensé aux autres mondes qu'avait pu

\footnotetext{
5 «...alors que les phrases pressent le “déroulement” de l'histoire (elles conduisent, déplacent l'histoire) le code herméneutique exerce une action contraire: disposer dans le flux du discours des retards (chicanes, arrêts, dévoiements)...» (BARTHES, 1970, p.81).
} 
créer Vinteuil comme à des univers clos, comme avait été chacun de mes amours ; mais, en réalité, je devais bien m'avouer que, comme au sein de ce dernier amour - ce lui pour Albertine - mes premières velléités de l'aimer (..) mes autres amours, n'y avaient été que de minces et timides essais qui préparaient des appels qui réclamaient ce plus vaste amour (...) et je cessais de suivre la musique pour me redemander si Albertine avait vu ou non Mlle Vinteuil... (PROUST, 1988a, pp.756-757)

Nesse trecho, o narrador apresenta elementos-chave para sua teoria final da arte. $\mathrm{O}$ elemento de verdade manifesta-se no momento em que explica como Vinteuil dispersou elementos distintos em sua composição para, ao final, serem combinados, produzindo uma unidade. Porém, essa "verdade" fica comprometida quando é utilizada não para uma análise da arte, mas para uma análise do amor. O equívoco surge porque essa comparação entre arte e amor é algo que não irá fazer parte da teoria final do narrador e será descartada nos modelos de Swann e Charlus.

Outro conceito que Barthes apresenta é o da "resposta parcial". Podemos encontrar uma manifestação dessa técnica no já mencionado episódio do Trocadero em La Prisonnière. O herói ainda sentado ao piano chega à conclusão que :

[...]la musique bien différente en cela de la société d'Albertine, m'aidait à descendre en moi-même, à y découvrir du nouveau (...) comme le spectre extériorise pour nous la composition de la lumière, l'harmonie d'un Wagner, la couleur d'un Elstir nous permettent de connaître cette essence qualitative des sensations d'un autre où l'amour pour un autre ne nous fait pénétrer. (PROUST, 1988a, p. 665).

Nesse "insight" do herói, há a indicação do caminho da vocação, mas não a teoria completa. Essa "resposta parcial" sobre a arte para o narrador continua no trecho sobre o septeto, quando o herói percebe que existe, prometido no começo dessa obra, algo mais misterioso que o amor de Albertine, pois: “...Vinteuil était mort depuis nombre d'années ; mais au milieu de ces instruments qu'il avait aimés, il lui avait été donné de poursuivre, pour un temps illimité, une part au moins de sa vie..." (PROUST, 1988a, pp. 758-759).

\section{O APRENDIZADO E O LEITOR:}

Nesse levantamento (não-exaustivo) das diferentes etapas do "código hermenêutico", percebe-se que o procedimento mais geral é o posicionamento, muitas vezes oposto, do herói em relação ao narrador. Genette trata desta mesma questão, sob um ponto de vista diferente. Ele não fala de "morfemas dilatadores" e sim de momentos nos quais o narrador "assume" uma opinião diferente da que tem. O narrador "fingiria" uma opinião da qual não compartilha para poder criar a ilusão do aprendizado. Genette (1972, pp. 214-215) mostra a técnica narrativa utilizada por Proust para conseguir isso é:

[...] bien souvent la focalisation interne sur le héros. C'est en général le 'point de vue du héros' qui commande le récit, avec ses restrictions de champ, ses ignorances momentanées, et même ce que le narrateur considère à part soi comme des erreurs de jeunesse, des naïvetés, des 'illusions à perdre'. Proust a insisté, dans une célèbre lettre à Jacques Rivière, sur le souci qu'il avait de dissimuler le fond de sa pensée (qui s'identifie ici à celle de Marcel-narrateur). La pensée apparente des dernières pages de 
Swann (dont on se rappelle pourtant qu'elles relatent une expérience en principe toute récente) est, dit-il avec force, " le contraire de ma conclusion'. Elle est une étape (...) pour l'instant, il faut respecter l'ignorance du héros, ménager l'évolution de sa pensée, le lent travail de la vocation ...

Mas qual seria a necessidade narrativa dessas "etapas", desse lento trabalho da vocação? Qual é, afinal, o sentido dessa "longa demonstração" que Proust tanto prezava? Se voltarmos a Fraisse 6 , podemos perceber que ele, quando trata dos "erros" e "incertezas" diz que, na verdade, é o leitor que tem de atravessá-los. Assim, o problema narrativo que Barthes descreve como "código hermenêutico" e que, como sabemos, Proust chama de "longa demonstração", pode ser entendido como o caminho que o leitor deve percorrer na atualização do texto. Esse também é o ponto de vista de Antoine Compagnon (2003, p. 146) que diz que:

[...]em $S / Z$, o código que (Barthes) denomina "hermenêutico" é definido como um conjunto de enigmas que compete ao leitor desvendar como faz um caçador ou um detetive, através de um trabalho com os índices. Estes são desafios, pequenas sacudidelas de sentido. Sem esse trabalho o livro fica inerte...

Na Recherche, a verdade sobre a vocação, descoberta pelo narrador ao final do $L e$ Temps Retrouvé, é também vivenciada pelo leitor. Talvez não estejamos tão longe do que Willemart (2000, p. 20) tratava quando explicou que:

[...]os numerosos cadernos, base das obras Jean Santeuil, Contre SainteBeuve e A Busca do Tempo Perdido indicam suficientemente o quanto Proust procurava quebrar um Simbólico que lhe era perfeitamente familiar teorizando de início e misturando em seguida, suas teorias estéticas com a ficção, meio exemplar de que dispõe o escritor para convencer os leitores e abalar seu Simbólico...

Nesse abalo ao Simbólico do leitor encontra-se a idéia de que ele "est quand il lit le propre lecteur de soi-même" e a obra "n'est qu'une espèce d'instrument optique qu'il offre au lecteur afin de lui permettre de discerner ce que sans ce livre il n'eût peut-être pas vu en soimême" (PROUST, 1998b, pp. 489-490). Isso só é possível porque os diferentes fragmentos, dispostos na ordem em que estão, levam o leitor a vivenciar a mesma revelação pela qual passa o narrador ao final do Temps Retrouvé. Essa seria, então, a verdadeira unidade da Recherche e que surge sem que se tenha de recusar a multiplicidade do texto proustiano. Basta, para isso, lembrarmos do ponto desenvolvido por Calvino (1990, p. 126) na conferência sobre a multiplicidade em que afirma que:

[...]Nem mesmo Proust consegue ver o fim de seu romance-enciclopédia, mas não de certo por falta de planejamento, dado que o projeto da Recherche nasce como um todo, princípio, fim e linhas gerais, mas porque a obra vai se adensando e dilatando em seu interior por força de seu próprio sistema vital. A rede que concatena todas as coisas é também o tema de Proust; mas em Proust esse rede é feita de pontos espaço-temporais

\footnotetext{
${ }^{6}$ «...une grande œuvre, aux yeux de Proust, doit être baignée de mystère (...) Ce livre, d'une 'composition voilée mais rigoureuse', 'd'une composition si préméditée et complexe' oblige le lecteur à suivre une sorte de stage, sous l'autorité du romancier. S'engageant dans un itinéraire minutieusement préparé pour lui, le lecteur doit traverser de nombreux moments d'incertitude et même d'erreur, pour qu'à la fin la vérité, la certitude, la compréhension se fassent jour dans tout leur éclat... ( FRAISSE, 1995, p.102).
} 
ocupados sucessivamente por todos os seres, o que comporta uma multiplicação infinita das dimensões do espaço e do tempo. O mundo dilata-se a tal ponto que se torna inapreensível,e para Proust o conhecimento passa pelo sofrimento dessa inapreensibilidade. Nesse sentido, o ciúme que o narrador prova por Albertine é uma típica experiência do conhecimento...

Portanto, de acordo com o escritor italiano, faz parte da experiência do conhecimento (ou do aprendizado) esse sofrimento pela inapreensibilidade. Ora, o leitor vivencia exatamente isso quando, na construção das perspectivas, experimenta a angústia do esquecimento na leitura de uma obra tal vasta quanto a Recherche, isso sem falarmos do caleidoscópio de perspectivas proposto. A multiplicidade de que fala Calvino é parte fundamental da experiência de leitura e da construção do leitor implícito. Assim, não há muito sentido em tomar partido de uma posição a favor ou contra a existência do elemento de construção no romance proustiano ${ }^{7}$ se o leitor quer, como explica Eco (2004, p. 43) "interpretar" esse tipo de texto múltiplo em oposição ao seu "uso como estímulo imaginativo". Afinal, não seria o papel proposto ao leitor exatamente aquele do "gigante" que toca simultaneamente os vários fragmentos do texto, "tão distantes- entre os quais tantos dias cabem - no Tempo" ${ }^{8}$ (PROUST, 1988b, p. 625) ? d

\section{Referências bibliográficas :}

BARTHES,Roland. S/Z. Paris : Editions du Seuil,1970.

«Longtemps, je me suis couché de bonne heure ». Oeuvres complètes Tome V. Paris : Editions du Seuil, 2002.

CALVINO, I. Seis propostas para o próximo milênio. São Paulo: Companhia das Letras, 1990.

COMPAGNON, Antoine. O demônio da teoria - Literatura e senso comum. Belo Horizonte: Editora UFMG, 2003

DELEUZE, Giles . Proust e os signos. Rio de Janeiro: Editora Forense-Universitária, 1987.

\footnotetext{
${ }^{7}$ É o que faz, num certo aspecto, Deleuze quando afirma que "o essencial é que as partes da Recherche permanecem divididas, fragmentadas, sem que nada lhes falte: partes eternamente parciais levadas pelo tempo, caixas entreabertas e vasos fechados, sem formar nem supor um todo, sem nada faltar nessa divisão, e denunciando de antemão toda unidade orgânica que se queira introduzir. Quando Proust compara sua obra a uma catedral ou a um vestido não é para defender um Logos como bela totalidade, mas, ao contrário, para defender o direito ao inacabado, às costuras e aos remendos..." (Op. cit.,, p.161). Para resolver esse problema, Deleuze coloca no narrador a unidade dos fragmentos. Ele seria a "estrutura formal da obra de arte" que em Proust se traduz na "transversalidade" ou na " nova convenção lingüística, a estrutura formal da obra, que atravessa toda frase (...) assim é o tempo, a dimensão do narrador, que tem o poder de ser o todo dessas partes, sem totalizá-las, a unidade de todas as partes, sem unificá-las..." (Op. cit., pp. 196/170).O narrador, aranha ou corpo sem órgãos, ser involuntário, tece a Recherche a partir da vibração de seu corpo e é ele, portanto, que dá unidade ao texto. É claro que Deleuze está tentando evitar a unidade orgânica, a metáfora animal, o Logos, pois sua leitura, a partir da filosofia, quer dar conta de um mundo fragmentado, em meio ao caos, onde essa unidade orgânica perdeu-se para sempre. Não estou, de maneira nenhuma, negando essa leitura a partir da filosofia, mas ela deixa de fora outras dimensões do objeto literário que tentamos aqui recuperar.
}

8 “....si distantes, entre lequelles tant de jours sont Venus se placer - dans le Temps”. (tradução nossa). 
ECO, Umberto. Lector in fabula. São Paulo: Editora Perspectiva, 2004.

FRAISSE, Luc . L'esthétique de Marcel Proust. Paris : Sedes, 1995.

GENETTE, Gerard. Figures III. Paris : Editions du Seuil, 1972.

MULLER, Marcel. Les voix narratives dans la Recherche du Temps perdu. Genève : Droz, 1983.

PROUST, Marcel. À la Recherche du temps perdu - volume III. Paris : Gallimard, 1988a. À la Recherche du temps perdu - volume IV. Paris : Gallimard, 1988b.

TADIE, Jean -Yves. Proust et le roman. Paris : Editions Gallimard, 1971.

WILLEMART, P. Proust poeta e psicanalista. São Paulo: Ateliê Editorial, 2000. 